DOI 10.20396/ideias.v8i1.8649784

\title{
Teoria Crítica, velhos e novos desafios: entrevista com Andrew Feenberg ${ }^{1}$
}

\author{
Bruna Della Torre de Carvalho Lima \\ Eduardo Altheman Camargo Santos ${ }^{3}$
}

Andrew Feenberg é professor na Universidade Simon Fraser em Vancouver e detém a cátedra de Pesquisa em Filosofia da Tecnologia. Seu campo de pesquisa concentra-se na área de Teoria Crítica da Tecnologia e ele é conhecido por seu papel no desenvolvimento no primeiro programa de educação online na Califórnia em 1980. Dentre as suas inúmeras publicações na área estão Critical Theory of Technology (1991), Alternative Modernity (1995) e Questioning Technology (1999). No entanto, além de ser um filósofo da tecnologia, Feenberg é um importante estudioso da Escola de Frankfurt, tendo inclusive escrito seu doutorado, cuja publicação data de 1973, sob a supervisão de Herbert Marcuse. Além dos livros Lukács, Marx and the Sources of Critical Theory (1986) e Transforming Technology. Heidegger and Marcuse: The Catastrophe and Redemption of History (2005), Feenberg lançou recentemente a obra The Philosophy of Praxis: Marx, Lukács and the Frankfurt School, na qual busca compreender as mutações da filosofia da práxis

\footnotetext{
${ }^{1}$ Recebida em 08/08/2016 e aprovada em 29/12/2016.

${ }^{2}$ Doutoranda em Sociologia pela Universidade de São Paulo (USP) e bolsista da Coordenação de Aperfeiçoamento de Pessoal de Nível Superior (CAPES). Contato: bru.dellatorre@gmail.com.

${ }^{3}$ Doutorando em Sociologia pela Universidade de São Paulo (USP) e bolsista do Conselho Nacional de Desenvolvimento Científico e Tecnológico (CNPq). Contato: eduardo.altheman@gmail.com.
} 
| 298 |

Teoria Crítica, velhos e novos desafios:...

desde suas formulações iniciais no jovem Marx até as grandes transformações que ela sofreu sob o crivo da pena da Escola de Frankfurt. Nesta entrevista, além de discutir seu novo livro, Feenberg fala sobre o pensamento crítico de Georg Lukács, Theodor W. Adorno, Herbert Marcuse, Jürgen Habermas e a New Left, entre outros temas, levando especialmente em consideração seu legado para a análise e a contestação do capitalismo contemporâneo.

Bruna Lima \& Eduardo Santos: Fredric Jameson, Slavoj Zizek, Stanley Aronowitz, entre outros intelectuais, têm escrito a respeito das possibilidades de uma nova práxis hoje. Alguns dizem que o comunismo não é mais uma opção e outros afirmam que, contra o império neoliberal do "não há alternativa", o maior desafio atual é reabrir a imaginação política para a ideia de que há de fato uma alternativa para substituir novamente a hegemonia da política de gabinete pela grande política, como Gramsci colocaria. E você acabou de escrever um livro sobre a filosofia da práxis e a relação entre teoria e práxis nas críticas de Marx, Lukács e da Escola de Frankfurt. Qual é sua posição a respeito da relação entre teoria e práxis hoje? Ainda é possível ser um marxista em um sentido ortodoxo?

Andrew Feenberg: Há duas questões aqui: o que é a teoria marxista e qual é a relação entre a teoria revolucionária e a práxis política. Vou responder em ordem.

Lukács afirma que a ortodoxia marxista é uma questão de método. Nesse sentido, sim, é possível ser um marxista ortodoxo. Mas parece que ninguém concorda com Lukács nesse ponto. Todos pensam que a ortodoxia marxista requer acreditar em alegações factuais específicas feitas por Marx ou por seus seguidores autorizados, como Lênin. O marxismo seria uma tradição teórica ou um "programa de pesquisa" baseado no pensamento deles. Devo dizer que sustento uma posição ambivalente a respeito dessa compreensão da teoria marxista. Tanta coisa mudou no mundo social e intelectual desde a consolidação dessa tradição nos anos seguintes à Revolução russa que apenas uma revisão relativamente drástica faz sentido hoje. E se ela ainda poderá ser chamada de marxista está certamente em questão. 
Deixe-me dar um exemplo no qual estou trabalhando no momento. Como nós localizamos a contribuição de Foucault em relação ao marxismo? Sua ênfase no papel da racionalidade na sociedade moderna, o que ele chama de "poder/saber", contrasta com a crítica da irracionalidade do capitalismo na tradição marxista. E ainda assim há uma conexão, uma vez que Marx inspirou a teoria de Weber da racionalização e a teoria da reificação de Lukács a ela relacionada. Nós podemos arranjar todas essas conexões de uma maneira que permaneça dentro da tradição marxista? Talvez, mas às custas de estender significativamente suas fronteiras. Nem todos concordariam com esse procedimento.

Quanto à segunda questão, há uma dificuldade: qual é a práxis revolucionária com a qual a teoria supostamente deve se relacionar? Trata-se do movimento trabalhista? Do movimento ambientalista? De um "novo partido comunista" ou um velho partido trotskista? Eu argumentaria que todos os vários movimentos sociais a favor de mudança progressista são a práxis com a qual nossa teoria deve se relacionar, mas também negaria que esses são movimentos revolucionários no sentido de Marx.

Nós somos confrontados com uma situação peculiar. O Manifesto comunista delineia reformas condicionadas ao sucesso da revolução, muitas das quais foram implantadas sob o capitalismo e sem revolução. Este é um processo contínuo. A revolução não aparece mais como a condição sine qua non para uma grande reforma progressiva. Foi possível afirmar em determinado momento que essas reformas sociais prematuras, como seguridade social, cooptaram a classe trabalhadora e integraram-na ao capitalismo. Este foi o grande argumento da Escola de Frankfurt. Mas agora, tantas reformas similares transformaram o capitalismo e a vida diária, e as expectativas revolucionárias estão tão reduzidas, que aquele argumento não é mais convincente.

Após a queda da União Soviética, sabemos o que queremos dizer com "socialismo"? Realmente queremos dizer que o movimento por direitos civis, o movimento das mulheres, o movimento ambiental, os movimentos por mudanças no sistema de saúde, e assim por diante, se integram no capitalismo às custas 
|300|

Teoria Crítica, velhos e novos desafios:...

de um potencial revolucionário que se assume estar em torpor nas massas? Não é mais provável que esses movimentos tenham colocado o capitalismo e as massas em um percurso evolutivo cujo futuro é imprevisível?

A teoria ainda pode desempenhar um papel nessa situação. Precisamos reconstruir a ideia de socialismo e a dinâmica dos movimentos por reforma, suas formas de protesto e comunicação, suas interações com estruturas técnicas e administrativas; tudo isso é um indício de inovações políticas que podem assumir uma importância crescente em uma nova forma de sociedade socialista.

BL\&ES: Em seu livro, você afirma que a diferenciação entre teoria tradicional e teoria crítica foi diretamente possível por causa da renovação da dialética que Lukács, Korsch e Bloch realizaram. Como você vê a relação da teoria crítica com outras fontes, especialmente as não marxistas, como a fenomenologia e Heidegger, ou a crítica da racionalização de Weber, ou a psicanálise de Freud, por exemplo?

AF: A teoria crítica foi transformada por Habermas e cortada de suas raízes na tradição anterior do marxismo dialético. Esta seria a principal nova fonte com a qual o marxismo dialético se relaciona hoje. Não é produtivo simplesmente ignorar Habermas. Suas inovações teóricas são importantes, mas elas parecem presas a um momento histórico específico que passou tão completamente quanto o momento no qual a Escola de Frankfurt primeiro desenvolveu sua abordagem. Eu tentei aprender com Habermas ao mesmo tempo em que recuperava a preocupação central com a tecnologia da primeira geração. A tecnologia desaparece da obra de Habermas relativamente cedo, no que parece ser uma concessão inaceitável à autoridade tecnocrática. Infelizmente para Habermas, ele elaborou sua posição antes do movimento ambiental completamente descreditar a tecnocracia e provar que pessoas comuns podem intervir produtivamente na orientação do desenvolvimento técnico. Meu trabalho é baseado nas implicações desta situação para a crítica da tecnologia. 
A distinção de Habermas entre "sistema" e "mundo da vida" aponta para a dualidade das organizações e dos artefatos sociais modernos. Por um lado, eles exibem uma forma racional, enquanto, por outro, eles refletem escolhas e valores sociais. Mas Habermas tende a reificar essa distinção como se algumas instituições exemplificassem um lado da dualidade e outras instituições, o outro lado. Na realidade, ela atravessa todas as instituições e artefatos. Elaborar os "aspectos duplos" da vida social moderna pode recorrer aos recursos teóricos encontrados em Heidegger e Lukács. Esse é o programa geral do meu trabalho.

BL\&ES: Lukács viu a crise como uma possibilidade de quebrar, de alguma maneira, a aparência reificada de uma sociedade não contraditória e, logo, ela se apresenta para ele como uma oportunidade de reunir teoria e práxis. Você acha que ainda é possível sustentar essa tese? Especialmente se pensarmos a respeito da crise econômica global de $2008 .$.

AF: Eu acho que todas as instituições sociais e tecnologias da sociedade capitalista moderna são reificadas e que todos os movimentos de protesto que elas provocam estão engajados em práxis desreificantes. Lukács explicou reificação e desreificação em termos da relação entre forma e conteúdo sociais. As categorias da economia política são uma forma imposta em um conteúdo social que as transborda. Esse conteúdo é essencialmente o processo vital do proletariado que não pode ser contido em funções econômicas. Hoje, muitas formas são impostas por burocracias e outras instituições sociais sobre vidas humanas, com consequências similares.

Para compreender como isso se relaciona com sua questão, precisamos deixar claro o que Lukács quis dizer com "reunir teoria e práxis". Não acho que Lukács quis dizer que a práxis é reunida com a teoria quando ela implementa a ideia de Marx de uma revolução socialista. Tampouco esse conceito tem algo a ver com a teoria se subordinando ao partido ou à classe. Isso é tomar ao contrário tudo o que Lukács tem em mente. O ponto não é que 
a práxis se conforma a uma ideia teórica pré-concebida ou viceversa, mas algo muito mais sutil e complicado. E especialmente interessante!

A teoria, para Lukács, é o prolongamento da consciência de classe e a própria consciência de classe deve ser compreendida como uma espécie de método prático, como uma maneira de compreender e abordar problemas práticos. A teoria marxista é baseada na abordagem metodológica que é derivada da práxis da classe trabalhadora. Como Marx diz (mais ou menos) no Dezoito Brumário, a teoria emprega os mesmos meios para solucionar no pensamento os problemas que a práxis soluciona na vida. A unidade entre teoria e práxis depende da classe se desreificar e se ressignificar, assim como ressignificar seu local na sociedade. Isto, por sua vez, permite à teoria alcançar uma compreensão desreificada da sociedade como um todo.

A aproximação mais adjacente a isso na história política recente é a função da consciência no movimento das mulheres. Uma nova autocompreensão está ligada a novas práxis e dá origem a uma nova teoria. Há, é claro, uma diferença: a consciência de classe tem o poder de ressignificar não apenas a identidade dos trabalhadores, mas de superar a sociedade que depende de que trabalhadores obedeçam a todas as obrigações que fluem daquela identidade. Nenhum dos movimentos sociais recentes tem esse potencial de transformar o sistema.

BL\&ES: Você afirma em seu livro que um dos problemas de Lukács em compreender a generalização do processo de reificação é o fato de ele não ter nem uma teoria da reificação inspirada na psicanálise e nem uma teoria dos meios de comunicação. Em sua opinião, qual o papel que os meios de comunicação têm na teoria crítica da Escola de Frankfurt? Qual você acha que é o lugar da indústria cultural, para citar o conceito de Adorno e Horkheimer, no presente bloqueio da práxis?

AF: As primeiras transmissões de rádio comercial nos EUA começaram nos anos de 1920 e a televisão apenas alcançou a população como um todo após a segunda guerra mundial. É normal 
que Marx tenha subestimado o impacto de poderosas tecnologias que emergiram somente gerações após sua morte. A Escola de Frankfurt foi contemporânea dessas tecnologias e reconheceu sua importância. O que eles testemunharam foi a construção de uma nova cultura baseada não no ambiente cultural de Marx, no qual as opiniões eram formadas em uma luta entre instituições religiosas, comunicação em meio a um público letrado e produção artística, mas sim por emissões sob o controle de corporações e políticos. A indústria cultural é a tomada de controle da esfera pública pelos negócios e pela propaganda. Não pode haver dúvida de que este é o fator principal no rebaixamento da cultura e da política hoje.

Entendo que existam redutos acadêmicos desesperados por alguma espécie de reciprocidade virtuosa entre audiências e emissores (são chamados de "estudos culturais"), mas quem pode levar isso a sério na era da negação ambiental e de Trump? Por favor, dá um tempo! Os meios de comunicação são realmente a força dominante em promover movimentos políticos conservadores, exatamente como aqueles marxistas fora de moda da Escola de Frankfurt alegaram há muito tempo.

BL\&ES: Em uma fala recente na Conferência Internacional de Teoria Crítica de Roma, em maio de 2016, você falou a respeito da importância de Lukács para a Escola de Frankfurt. O título de sua apresentação foi, provocativamente, "Por que os alunos da Escola de Frankfurt terão de ler Lukács". Parece que hoje em dia há uma renovação da Escola de Frankfurt que não inclui nem Marx e nem Lukács em seus programas. Como você vê isso e quais são as armadilhas a que tal maneira de ler a teoria crítica pode levar?

AF: Suponho que por renovação da Escola de Frankfurt você queira dizer alguma combinação de Habermas, Honneth e leituras estreitamente exegéticas de Benjamin e de Adorno. Devo admitir que valorizo todos esses desvios de uma compreensão política radical da Escola de Frankfurt. Mas o faço como acadêmico, isto é, como alguém curioso em relação a questões acadêmicas. A questão maior dessa renovação da Escola de Frankfurt é um 
assunto diferente. Sim, podemos aprender todas as sortes de coisas importantes e interessantes por meio das atuais tendências de interpretação da Escola de Frankfurt, mas precisamos de mais do que essas tendências podem oferecer. Precisamos ver a relevância dessa tradição para as lutas políticas ocorrendo hoje. A melhor maneira de atingir esse objetivo é retornar a Marx e a Lukács, as influências mais importantes sobre a política dos pensadores da Escola de Frankfurt.

BL\&ES: Hoje em dia parece haver uma crítica generalizada à Escola de Frankfurt que tenta denunciar o suposto elitismo e eurocentrismo presente em suas teorias. Tal denúncia tomaria sua crítica por insuficientemente radical, por obsoleta e uma consequência do mandarinismo alemão. Além disso, parece levar a uma negação completa da Escola de Frankfurt e de seus trabalhos. Como você zê o radicalismo da teoria crítica hoje?

AF: Estou farto desta conversa fiada a respeito da esquerda acadêmica. Pessoas demais estão empurrando seus "produtos" por meio de propaganda negativa. Quaisquer que sejam as falhas da Escola de Frankfurt, ela tem muito a contribuir. Eu compareci a uma das últimas palestras de Foucault nos EUA. Antes de ler sua palestra, ele abriu com um discurso de quinze minutos elogiando a Escola de Frankfurt e negando que ele havia abolido o sujeito, uma leitura banal de sua obra então. Na verdade, ele disse, a Escola de Frankfurt havia antecipado algumas de suas ideias mais importantes e todo seu esforço consistiu em compreender o sujeito. Eu tomei isso como uma crítica devastadora de Foucault a seus epígonos americanos que pensavam que ele poderia ser usado para bater em seus adversários intelectuais, aqueles terríveis paleo-marxistas da Escola de Frankfurt.

BL\&ES: Vamos discutir especificamente a crítica de Adorno à New Left. Você acredita que sua apreciação teria sido a mesma se ele tivesse vivido, digamos, em Paris, onde trabalhadores e estudantes marcharam lado a lado, pedindo por greve geral, "imaginação no poder", 
"demandemos o impossível", e assim por diante? Você não acha que sua crítica ao acionismo desesperado da New Left tem muito mais a ver com a situação específica da Alemanha e dos EUA, nos quais grupos isolados não conseguiam unir-se e formar um grupo maior de contestação do capitalismo?

AF: A crítica de Adorno à New Left é embaraçosa. Isso é crítica de gabinete, perante o nível do grande desafio político que ele vivenciou quando o Instituto de Frankfurt foi ocupado por seus estudantes. É claro que ele ficou chateado, mas você tem que saber lidar com esse tipo de coisa se você é um pensador revolucionário. Quando várias alunas tiraram sarro dele expondo seus seios em seu seminário, ele deveria ter pedido a elas para se aproximarem, e não fugir indignado com a falta de piedade acadêmica delas. O pobre rapaz...

Acho difícil compreender a atitude do Adorno. Marcuse se engajou com alunos, muitos dos quais eram tão narcisistas e confusos quanto os de Adorno, mas ele os criticou de dentro do movimento, não como um estranho diagnosticando uma doença. Embora o movimento estudantil alemão possa ter sido particularmente desagradável, certamente Adorno estava ciente das lutas heroicas pelos direitos civis nos EUA e do vasto movimento popular na França em 1968. Por que ele foi tão provinciano em sua avaliação da New Left, como se suas próprias experiências infelizes fossem de importância histórico-mundiais? É um mistério para mim.

BL\&ES: Por outro lado, Marcuse tornou-se famoso por ser o guru da New Left, o assim chamado maître à penser das barricadas. Mas você não acha que este também é um reducionismo de Marcuse, no sentido de que sua teoria nunca é realmente discutida? Seu ativismo político parece contar muito mais e ser a sua única contribuição para a teoria crítica. Como você zêe esses diferentes ritmos da filosofia e da política, como Habermas colocou essa questão? 
|306 |

Teoria Crítica, velhos e novos desafios:...

AF: A subestimação de Marcuse hoje é um sinal da degradação da esquerda acadêmica. Alguns pensadores sérios, como Bernard Stiegler, continuam a debater com seu pensamento, mas muitos outros simplesmente tiram vantagens de temas de sua obra sem atribuição e contam com a ignorância de sua audiência para conseguir créditos pelas ideias que ele havia explorado primeiro.

Há dois fatos extraordinários sobre essa situação. Antes de O homem unidimensional vender 300 mil cópias, quase ninguém no mundo anglófono sabia o que a Escola de Frankfurt era. Ela era uma nota de rodapé em livros de história intelectual escritos por acadêmicos liberais como H. Stuart Hughes, e não uma presença a se levar em consideração. O homem unidimensional ainda é o único livro da Escola de Frankfurt a ter um impacto político significativo. O segundo fato extraordinário é que a carreira de Marcuse como filósofo começa com uma publicação em 1928 e continua até sua morte em 1979 com dezenas de artigos interessantes e muitos livros dignos de atenção de filósofos e de historiadores intelectuais. Não há nada de errado com esse corpus de trabalho que deveria levá-lo a ser rebaixado ou ignorado porque Marcuse esteve brevemente sob escrutínio público. Ele não saiu procurando publicidade. As pessoas vieram a ele.

Há uma diferença importante entre Marcuse e Adorno e Horkheimer que deveria nos interessar hoje. Apenas Marcuse compreendeu o significado prefigurativo da New Left. Apenas ele viu as novas possibilidades de oposição que haviam emergido mesmo quando a resistência da classe trabalhadora ao capitalismo enfraqueceu. Certamente nós precisamos entender esse fenômeno e Marcuse pode contribuir para essa tarefa, ao passo que encontro menos auxílio em seus colegas da Escola de Frankfurt. 